\title{
Pulmonary air leak in extremely low birthweight infants
}

\author{
V Y H YU, P Y WONG, B BAJUK, AND W SZYMONOWICZ \\ Department of Paediatrics, Queen Victoria Medical Centre, Melbourne, Australia
}

SUMmARY The incidence of pulmonary air leak in 230 infants with a birth weight of 500-999 $\mathrm{g}$ who were ventilated was $41 \%$. Pulmonary interstitial emphysema occurred in $35 \%$, pneumothorax in $20 \%$, pneumomediastinum in $3 \%$, and pneumopericardium in $2 \%$. The survival rates in those with or without pulmonary air leak were not significantly different in the first four years of the study period $(46 \% v 53 \%)$. As the survival improved in infants without air leak during the second four years the difference in survival rates in infants with or without air leak became significant $(30 \% \vee 71 \%)$. Effective measures of preventing pulmonary air leak are required before further improvement in the outcome of these extremely low birthweight infants can be achieved.

As increasing numbers of infants weighing less than $1000 \mathrm{~g}$ at birth are actively treated with neonatal intensive care and more are surviving one major complication of mechanical ventilation that has emerged in this extremely low birthweight population is pneumothorax and other forms of air leak. Although it has been shown that pulmonary air leaks occur more frequently in infants with lower birth weights, ${ }^{1}$ its incidence in extremely low birthweight infants has not been reported. The present study was undertaken to survey the range of pulmonary air leak in a large extremely low birthweight population and to describe its incidence, clinical course, and effect on survival.

\section{Patients and methods}

A total of 249 infants weighing $500-999 \mathrm{~g}$ at birth were admitted to the Queen Victoria Medical Centre during the eight year period January 1977 to December 1984. Of these, $230(92 \%)$ received mechanical ventilation. The primary respiratory diagnoses in these infants were hyaline membrane disease in $126(55 \%)$, apnoea of prematurity in 69 $(30 \%)$, pneumonia in $21(9 \%)$, and respiratory depression from birth asphyxia in $14(6 \%)$.

All infants had serial chest $x$ ray films taken daily at least for the first 10 days after birth while on mechanical ventilation. The radiological diagnosis of the various forms of pulmonary air leak was made in the course of management in these infants. Pulmonary interstitial emphysema was diagnosed when a coarse reticular pattern of linear and rounded radiolucencies was seen extending out from the hilum. As air dissected around the thymus a typical sail sign was considered diagnostic of pneumomediastinum, especially in the lateral projection. Large pneumothoraces were readily recognised radiologically by air outlining the lung along its lateral margin, though small pneumothoraces were only seen medially as a crescent lucency next to the heart. Pneumopericardium was diagnosed when air was seen around the heart.

Our management of respiratory failure in extremely low birthweight infants has been described previously. ${ }^{2}$ Pulmonary interstitial emphysema was managed conservatively with physiotherapy and by nursing the infant on the side that was most affected, ${ }^{3}$ except in severe cases when muscle paralysis ${ }^{4}$ and high frequency low positive pressure hand ventilation ${ }^{5}$ were used. Pneumothoraces were drained through the lateral or superior thoracostomy approach. The chest drain was connected to 5-10 $\mathrm{cmH}_{2} \mathrm{O}$ negative suction and removed when the lung had re-expanded and drainage ceased for 24 hours. No specific treatment was given for pneumomediastinum. In the case of cardiac tamponade resulting from pneumopericardium needle aspiration of the pericardial sac through a substernal approach was undertaken. An indwelling pericardial drain was used when there was recurrence of tamponade.

The clinical criteria used for the diagnosis of hyaline membrane disease ${ }^{2}$ and bronchopulmonary 
dysplasia $^{6}$ have previously been described. Hyaline membrane disease was diagnosed clinically if the following criteria were present: respiratory distress not attributable to other causes; diffuse, finely granular opacities on chest $x$ ray film persisting at least till the third day; oxygen requirement over $30 \%$ beginning during the first 12 hours and lasting at least three days; and a maximum oxygen requirement of over $40 \%$. The diagnosis of bronchopulmonary dysplasia was made when chronic respiratory distress developed on assisted ventilation; treatment with oxygen was required for more than 28 days; and irregular and linear strands of dense opacities alternating with areas of normal or increased lucency were seen on chest $x$ ray film. The $\chi^{2}$ test and the Student's $t$ test were used for statistical analysis.

\section{Results}

Incidence. Ninety five infants had one or more form of pulmonary air leak. All developed pulmonary air leak during mechanical ventilation except one with a spontaneous pneumothorax. The incidence of pulmonary air leak in ventilated infants was therefore $41 \%$ (94 of 230 ). The annual incidence of all pulmonary air leaks varied between $21 \%$ and $50 \%$ with no obvious trend over the eight years. Of the 230 ventilated infants, $80(35 \%)$ had pulmonary interstitial emphysema, $47(20 \%)$ had pneumothorax, eight $(3 \%)$ had pneumomediastinum, and five $(2 \%)$ had pneumopericardium.

Table 1 shows the incidence of pulmonary air leak according to $100 \mathrm{~g}$ birthweight categories. A significant trend in decreasing incidence with increasing birth weight was observed $(p<0 \cdot 01)$.

Clinical data. The primary respiratory diagnoses in the 94 infants who developed pulmonary air leaks on mechanical ventilation were hyaline membrane disease in $74(79 \%)$, pneumonia in nine $(10 \%)$, apnoea of prematurity in six $(6 \%)$, and respiratory depression from birth asphyxia in five $(5 \%)$. The median

Table 1 Incidence of air leak in ventilated infants according to the birth weight

\begin{tabular}{lll}
\hline Birth weight $(g)$ & No of infants & No $(\%)$ with air leak \\
\hline $500-599$ & 14 & $6(43)$ \\
$600-699$ & 37 & $21(57)$ \\
$700-799$ & 47 & $22(47)$ \\
$800-899$ & 77 & $30(39)$ \\
$900-999$ & 55 & $15(27)$ \\
\hline Total & 230 & $94(41)$ \\
\hline
\end{tabular}

age of onset of pneumothorax was two days (range $1-6$ days). Twenty two (47\%) occurred on day 1 and another $15(32 \%)$ on day 2 . Twenty seven $(57 \%)$ of the pneumothoraces were preceded by or diagnosed at the same time as pulmonary interstitial emphysema. The pneumothorax was unilateral in 24 $(51 \%)$, occurring with equal frequency on the left or right side.

Morbidity. In survivors with pulmonary air leak the median duration of treatment with oxygen was 49 days (range 6-243 days), and the median duration of ventilation was 34 days (range 2-115 days). Sixteen $(47 \%)$ of 34 ventilated survivors with pulmonary air leak developed bronchopulmonary dysplasia compared with $29(34 \%)$ of 86 ventilated survivors without air leak.

Mortality. Of the 230 infants who received mechanical ventilation, $120(52 \%)$ survived. Table 2 shows the hospital survival of ventilated infants with and without pulmonary air leak. Those without air leak had a significantly higher survival rate than those with air leak $(p<0 \cdot 0005)$. The median age of death in infants with pulmonary air leaks was two days (range 1-11 days). Of the 111 extremely low birthweight infants who died during the study period, $60(54 \%)$ had pulmonary air leak.

During the years 1977-80 the overall survival rate in ventilated infants without air leak was not significantly lower than those with air leak (Table $3)$. The survival rate between the periods 1977-80 and 1981-84 had significantly improved $(\mathrm{p}<0.025)$ in those without air leak but was not significantly

Table 2 Survival according to birth weight. Data expressed as no of survivors/total no of infants (survival rate in \%)

\begin{tabular}{lcccrc}
\hline Birth weight $(g)$ & Air leaks & \multicolumn{2}{c}{ No air leaks } & \multicolumn{2}{c}{ All infants } \\
\hline $500-599$ & $2 / 6(33)$ & $1 / 8$ & $(13)$ & $3 / 14$ & $(21)$ \\
$600-699$ & $5 / 21(24)$ & $7 / 16(44)$ & $12 / 37$ & $(32)$ \\
$700-799$ & $7 / 22(32)$ & $18 / 26(69)$ & $25 / 48(52)$ \\
$800-899$ & $16 / 30(53)$ & $30 / 46(65)$ & $46 / 76(61)$ \\
$900-999$ & $4 / 15(27)$ & $30 / 40(75)$ & $34 / 55$ & $(62)$ \\
\hline Total & $34 / 94(36)^{*}$ & $86 / 136(63)^{*}$ & $120 / 230(52)$ \\
\hline
\end{tabular}

$* \mathrm{p}<0.0005$.

Table 3 Survival in ventilated infants according to year of birth. Data expressed as no of survivors/no of infants (survival rate in \%)

\begin{tabular}{llll}
\hline Year of birth & Air leaks & No air leaks & $p$ Value \\
\hline $1977-80$ & $17 / 37(46)$ & $31 / 59(53)$ & ns \\
$1981-84$ & $17 / 57(30)$ & $55 / 77(71)$ & $<0.0005$ \\
\hline
\end{tabular}


different in those with air leak. Consequently, during the period 1981-84 the survival rate in ventilated infants without air leak was significantly better $(\mathrm{p}<0 \cdot 0005)$ than those with air leak.

\section{Discussion}

No analysis of the entire range of pulmonary air leak has been reported in extremely low birthweight infants. The incidence of pulmonary interstitial emphysema in 57 extremely low birthweight infants was found to be $42 \%$ in one study, ${ }^{7}$ and that for pneumothorax in another series of 59 extremely low birthweight infants was $36 \% .{ }^{8}$ The overall incidence of pulmonary interstitial emphysema and pneumothorax was $35 \%$ and $20 \%$, respectively, in the present study. Our incidence of pneumothorax in the extremely low birthweight infants is no higher than the $20-40 \%$ reported in cohorts of ventilated infants who are more mature and have a higher birth weight. ${ }^{910}$ We have also shown that the overall incidence of pulmonary air leak was higher in infants of a lower birth weight even within this extremely low birthweight population, suggesting that the smaller or more immature the infant the higher is the risk to their lungs of iatrogenic barotrauma.

Although infants with more severe underlying lung disease were likely to require more vigorous ventilation, which increased the risk of pulmonary air leak, the survival rates in ventilated infants with or without air leak were not significantly different during the first four years of the study period. Similar findings were reported for pneumothorax in a recent study. ${ }^{8}$ As the survival rate in those without pulmonary air leak improved during the last four years of the study period the difference with that in infants with pulmonary air leak became significant. Efforts at improved detection and treatment of air leak have not improved survival during the last eight years. It remains important to try to prevent pulmonary air leaks during mechanical ventilation. Attempts to do this with muscle paralysis have given conflicting results; ${ }^{11}{ }^{12}$ selective paralysis of only those infants who actively expire against positive pressure ventilation, however, seems to be an effective method ${ }^{12}$ and deserves further investigation in an extremely low birthweight population.

\section{References}

${ }^{1}$ Madansky DL, Lawson EE, Chernick V, Taeusch HW. Pneumothorax and other forms of pulmonary air leak in newborns. Am Rev Respir Dis 1979;120:729-37.

$2 \mathrm{Yu}$ VYH, Hollingsworth E. Respiratory failure in infants weighing $1000 \mathrm{~g}$ or less at birth. Aust Paediatr J 1979;15:152-9.

Leonidas JC. Hall RT, Rhodes OG. Conservative management of unilateral pulmonary interstitial emphysema under tension. $J$ Pediatr 1975;87:776-8.

4 Greenough A, Dixon AK, Roberton NRC. Pulmonary interstitial emphysema. Arch Dis Child 1984;59:1046-51.

$5 \mathrm{Ng} \mathrm{KPK}$, Easa D. Management of interstitial emphysema by high-frequency low positive-pressure hand ventilation in the neonate. J Pediatr 1979;95:117-8.

6 Yu VYH, Orgill AA, Lim SB, Bajuk B, Astbury J. Bronchopulmonary dysplasia in very low birthweight infants. Aust Paediatr J 1983;19:233-6.

7 Hart SM, McNair M, Gamsu HR, Price JF. Pulmonary interstitial emphysema in very low birthweight infants. Arch Dis Child 1983;58:612-5.

${ }^{8}$ Greenough A, Roberton NRC. Morbidity and survival in neonates ventilated for the respiratory distress syndrome. $\mathrm{Br}$ Med J 1985;290:597-600.

${ }^{9}$ Monin P, Vert P. Pneumothorax. Clin Perinatol 1978;5:335-50.

10 Yu VYH, Liew SW, Roberton NRC. Pneumothorax in the newborn: changing pattern. Arch Dis Child 1975;50:449-53.

11 Pollitzer MJ, Reynolds EOR, Shaw DG, Thomas RM. Pancuronium during mechanical ventilation speeds recovery of the lungs with hyaline membrane disease. Lancet $1981 ; \mathbf{i}: 346-8$.

12 Greenough A, Wood S, Morley CJ, Davis JA. Pancuronium prevents pneumothoraces in ventilated premature infants who actively expire against positive pressure ventilation. Lancet $1984 ; \mathbf{i}: 1-4$

Correspondence to Professor V Y H Yu, Queen Victoria Medical Centre, 172 Lonsdale Street, Melbourne, Victoria 3000, Australia.

Received 18 November 1985 